Supporting Information

\title{
IN VIVO EVALUATION OF Zn FOLIAR UPTAKE AND TRANSPORT IN SOYBEAN USING X-RAY ABSORPTION AND FLUORESCENCE SPECTROSCOPY
}

Marcos H. F. Gomes ${ }^{1}$, Bianca A. Machado ${ }^{1}$, Eduardo S. Rodrigues ${ }^{1}$, Gabriel Sgarbiero Montanha1 ${ }^{1}$ Mônica Lanzoni Rossi ${ }^{1}$, Rafael Otto ${ }^{2}$, Francisco S. Linhares ${ }^{1}$, Hudson W. P. Carvalho ${ }^{1 *}$

${ }^{1}$ University of São Paulo, Centre for Nuclear Energy in Agriculture, Piracicaba-SP, 13416-000, Brazil.

2University of São Paulo, "Luiz de Queiroz" College of Agriculture, PiracicabaSP, 13418-900, Brazil.

\section{Email addresses for authors:}

Marcos H. F. Gomes: marcos.gomes@usp.br Bianca A. Machado: bianca.almeidamachado@usp.br Eduardo S. Rodrigues: eduardosr07@usp.br Gabriel S. Montanha: gabriel.montanha@usp.br Mônica L. Rossi: monicalr@cena.usp.br Rafael Otto: rotto@usp.br Francisco S. Linhares: fscaglia@cena.usp.br Hudson W.P. Carvalho: hudson@cena.usp.br, Tel: + 551934294737 


\section{Contents}

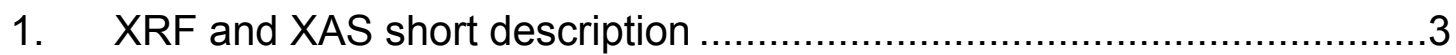

2. Absorption Test Setup ............................................................

3. Region Analyzed on the Kinetics Analysis .....................................

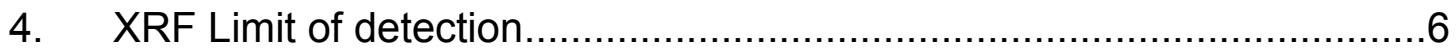

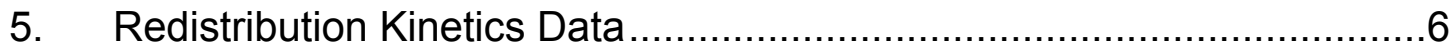

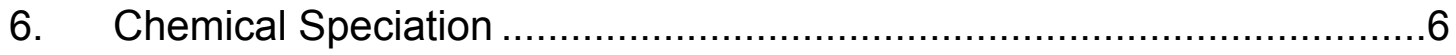

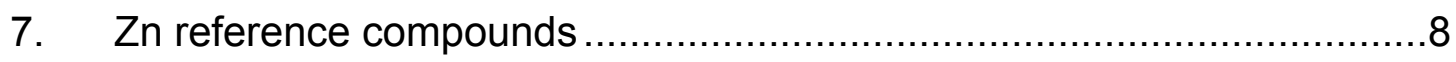

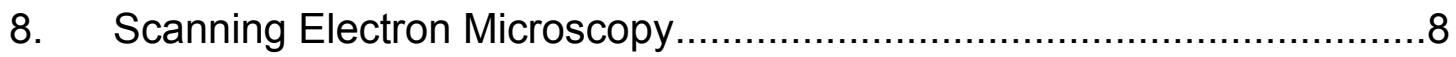

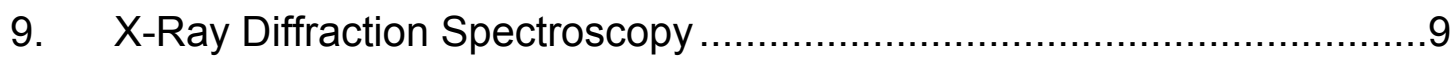

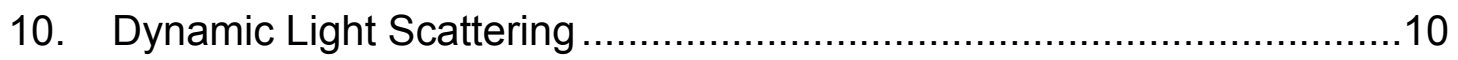

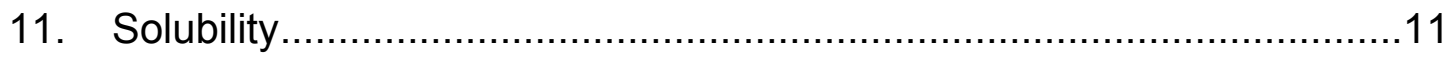

12. Penetration pathways thought the leaf blade .................................11

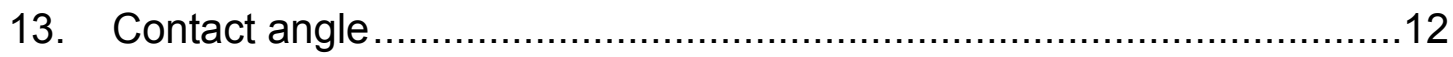

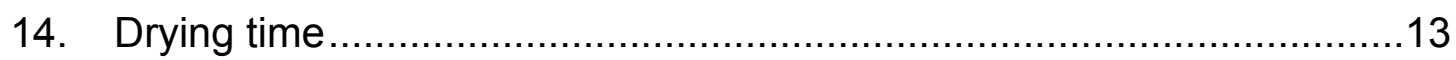

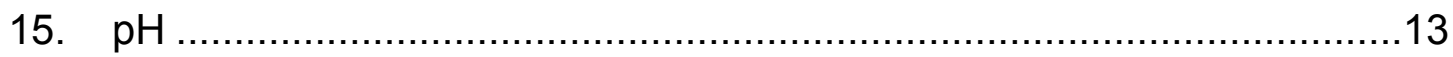

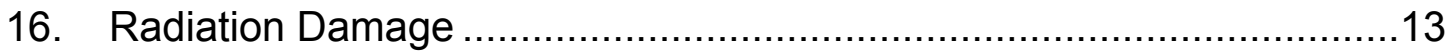

16.1. XRF Measurements ............................................................

16.2. Light Microscopy Analysis ................................................. 16 


\section{XRF and XAS short description}

$\mathrm{XRF}$ is promptly employed in the simultaneous identification and quantification of elements. This technique is available either in synchrotron radiation facilities or in benchtop commercial equipment. Synchrotron radiation has the advantage of higher photon brilliance and tuneable energy. Semi-quantitative measurements can be performed without calibration, while quantitative studies are either done with calibration by certified standards or with fundamental constants. Making use of small beam sizes in the range of micrometers (micro-XRF), the technique can be employed in mapping studies. The results of this procedure are chemical images that allow localizing and quantifying elements.

XAS is a powerful analytical element-specific tool. It is non-destructive and has only few interferences. At certain energies, a core shell electron can absorb an X-ray photon. The latter, in turn, can be either promoted to a higher unoccupied electronic level or ejected out of the atom. The ejected photoelectron may be regarded as a spherical wave travelling away from the absorber; this wave may be backscattered by the atoms in the surroundings of the absorber. The backscattered wave interferes with the on-going one. This phenomenon modulates the absorption coefficient of the absorber atom, and therefore structural and chemical information on the neighborhood can be obtained.

The XAS spectrum is usually divided into two complementary regions, the near absorption edge (XANES) and the extended fine structure (EXAFS). XAS provides the experimentalist information on the local chemical environment, usually $<6 \AA$ around the absorber. XANES is readily employed in speciation studies, the components of mixtures can be identified by combinatorial linear combination fittings using reference compounds spectra.

There are two features of XANES that makes it more suitable than EXAFS in the framework of the present study. Firstly, XANES comprehends a shorter spectral region, therefore recording a XANES spectrum is faster than an EXAFS one, which in turn leads to lower radiation doses and prevent radiation damage. Secondly, while EXAFS output gives a projection of the radial distribution of atoms around the absorber, XANES is in a certain point more influenced by the symmetry and angles between the central atoms and those in the neighbourhood. Therefore, similar ligands such as short organic molecules containing carboxyl groups which bind metals via $O$ atoms give different XANES spectra. 


\section{Absorption Test Setup}

To perform the absorption teste, the plants at the V3 phenological stage was assembled on an acrylic sample holder built specifically for this type of analysis (Figure S1A). This facility aims at preserve the plants alive during the trial conduction. The fertilizer was droplet up to a vein on the abaxial face of the leaf using a volumetric pipette (Figure S1B). Immediately after the application the plants were transferred to an acrylic chamber located inside a growth room aiming at maintain the humidity, photoperiod and temperature stable in $80 \%, 12$ hours and $27^{\circ} \mathrm{C}$ respectively during the analysis (Figure S1C). To perform the readings, the plants were loaded directly inside the EDAX Ametek Orbis PC $\mu$-XRF equipment (Figure S1D). and moved back to the acryclic chamber between the readings.

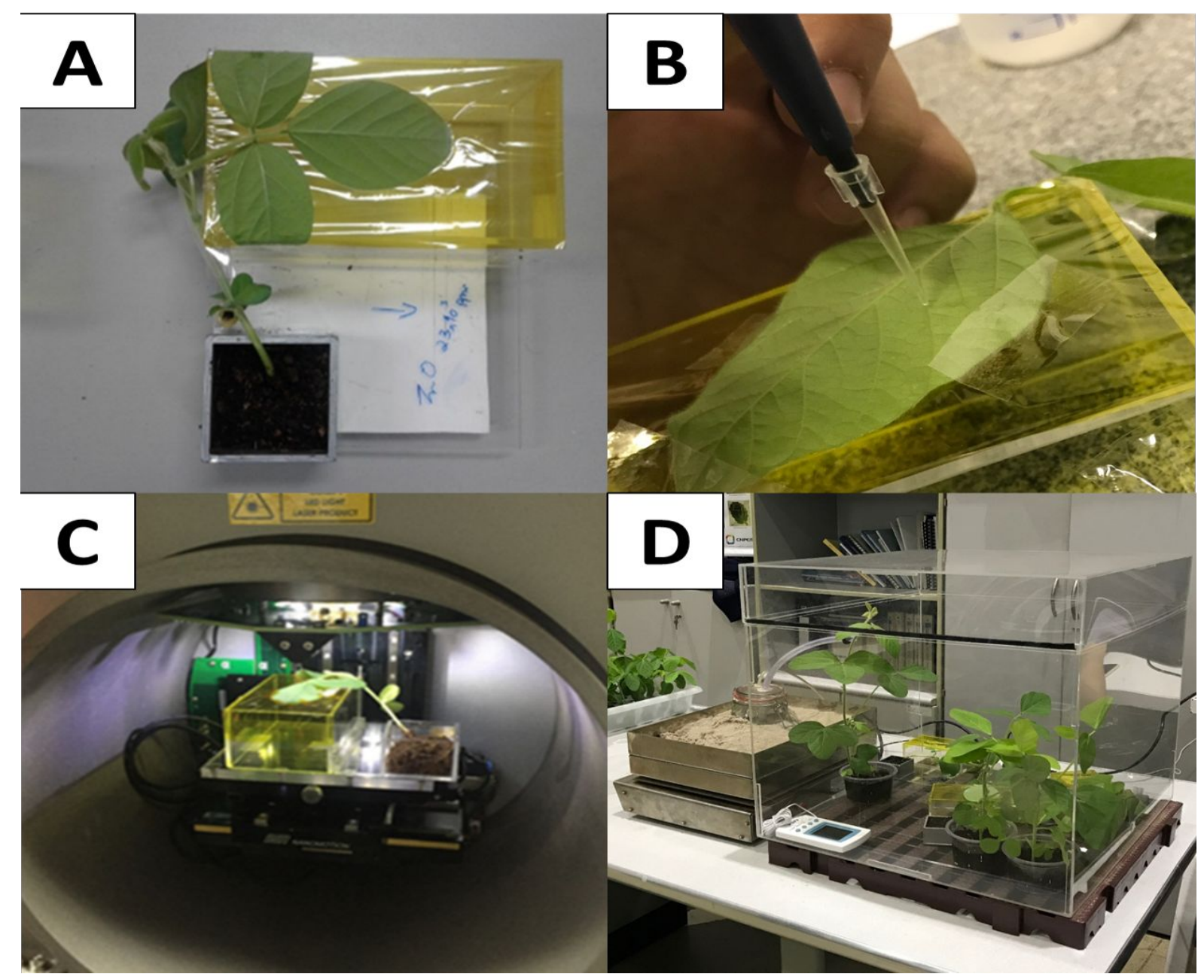

Figure S1. (A) Soybean plant assembled on the acrylic sample holder; (B) Dripping of the fertilizers up to the vein on the abaxial face a soybean leaf; $(C)$ Plants inside the 
acrylic chamber maintained in high humidity; (D) Soybean plant loaded inside the EDAX Ametek Orbis PC $\mu$-XRF equipment.

For better illustration of the $\mathrm{Zn}$ movement thought the vein when applied as sulphate, Figure S2 overlaps the Zn $\mu$-XRF map and the corresponding picture of the mapped area.
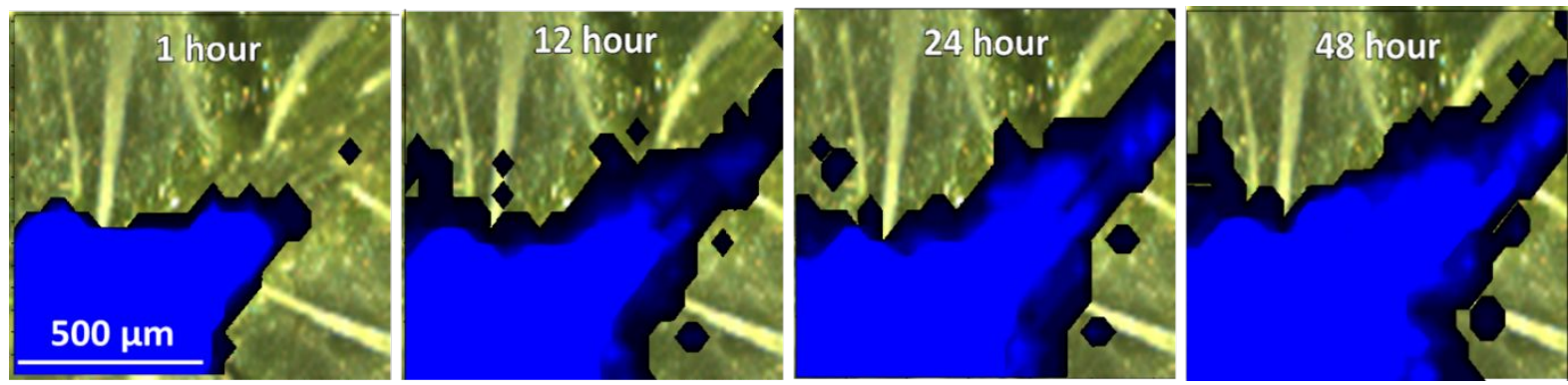

Figure S2. Overlap of the Zn $\mu$-XRF map and the corresponding picture of mapped area.

\section{Region Analyzed on the Kinetics Analysis}

Being the $\mathrm{X}$-Ray beam close to a cylinder it interacts with a region on the petiole close to a cylinder as shown in Figure S3.

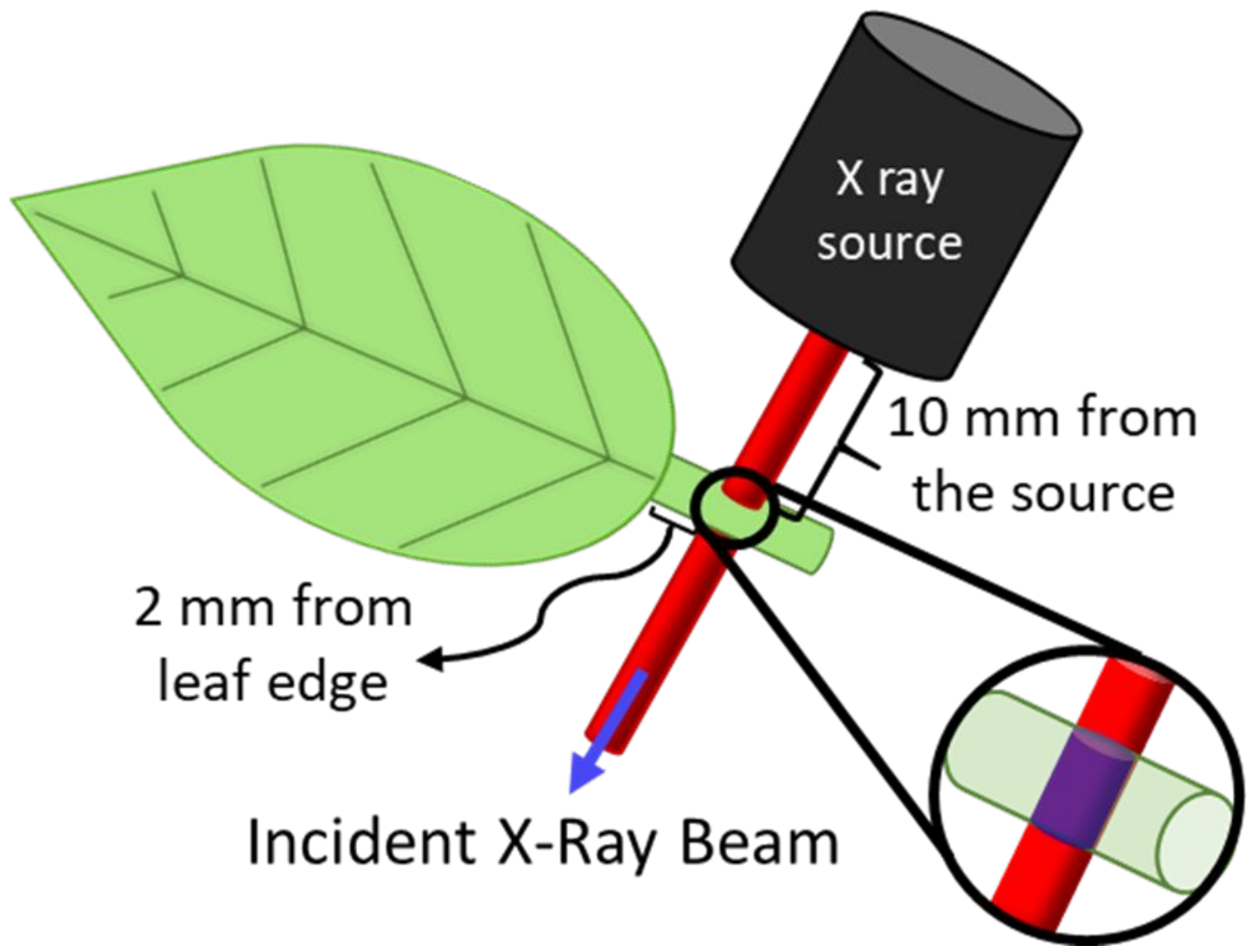

Figure S3. Scheme of the analyzed region on the Kinetics readings. 


\section{XRF Limit of detection}

The limit of detection for $\mathrm{Zn}$ in $\mathrm{mg} \mathrm{Kg}^{-1}$ on the samples was determined using the equation (1) The average background counts $\left(B G_{\text {mean }}\right)$ is the mean background value (cps) under the corresponding analyte Ka peak of the five randomly X-ray spectras selected in the analyzed region, and $t(s)$ is the acquisition time. The sensitivity (S) for $\mathrm{Zn}$ was calculated using a $\mathrm{Zn}$ thin film Micro Matter ${ }^{\mathrm{TM}}$ standard (Serial Number 6330) containing $16.16 \mathrm{mg} \mathrm{Zn} \mathrm{cm}^{-2}$. The superficial density (A) was obtained weighing a piece of soybean leaf with $1 \mathrm{~cm}^{2}$.

Limit of detection $\left(\mathrm{mg} \mathrm{kg}^{-1}\right)=\frac{3.3 * \sqrt{\frac{\sqrt{\left.G_{\text {mean }}\right)}}{\mathrm{t}(\mathrm{s})}}}{S\left(\mathrm{cps}_{\mu} \mathrm{g}^{-1} \mathrm{~cm}^{2}\right) * A\left(\mathrm{~g} \mathrm{~cm}^{-2}\right)}$

\section{Redistribution Kinetics Data}

Aiming at understanding the velocity of transport of zinc on the petiole it was analyzed the slope of the kinetics curves between 35 and 59 hours. It was noted that even elapsed 35 hour of the application the $\mathrm{Zn}$ applied as sulphate still been absorbed.

Table S1. Analysis of the slope of $\mathrm{Zn}$ concentration curves on the petiole between 35 and 59 hours after the application of the fertilizers.

\begin{tabular}{ccc}
\hline Sample & Slope $\left(Z n\right.$ counts hour $\left.{ }^{-1}\right) \times \mathbf{1 0}^{-5}$ & Pearson's $r$ \\
\hline Control & $0.85 \pm 0.25$ & 0.807 \\
ZnO & $1.07 \pm 0.17$ & 0.937 \\
ZnSO4 & $1.97 \pm 0.29$ & 0.945 \\
\hline
\end{tabular}

\section{Chemical Speciation}

To perform the chemical speciation of $\mathrm{Zn}$, firstly the plants were assembled in a plastic slide to facilitate the fixation. Then, the application procedures (dripping or spreading) were repeated as described before (Figure S4A and B). The plants were transferred to the acrylic chamber and loaded in the beamline to perform the readings (Figure S4C and D). 

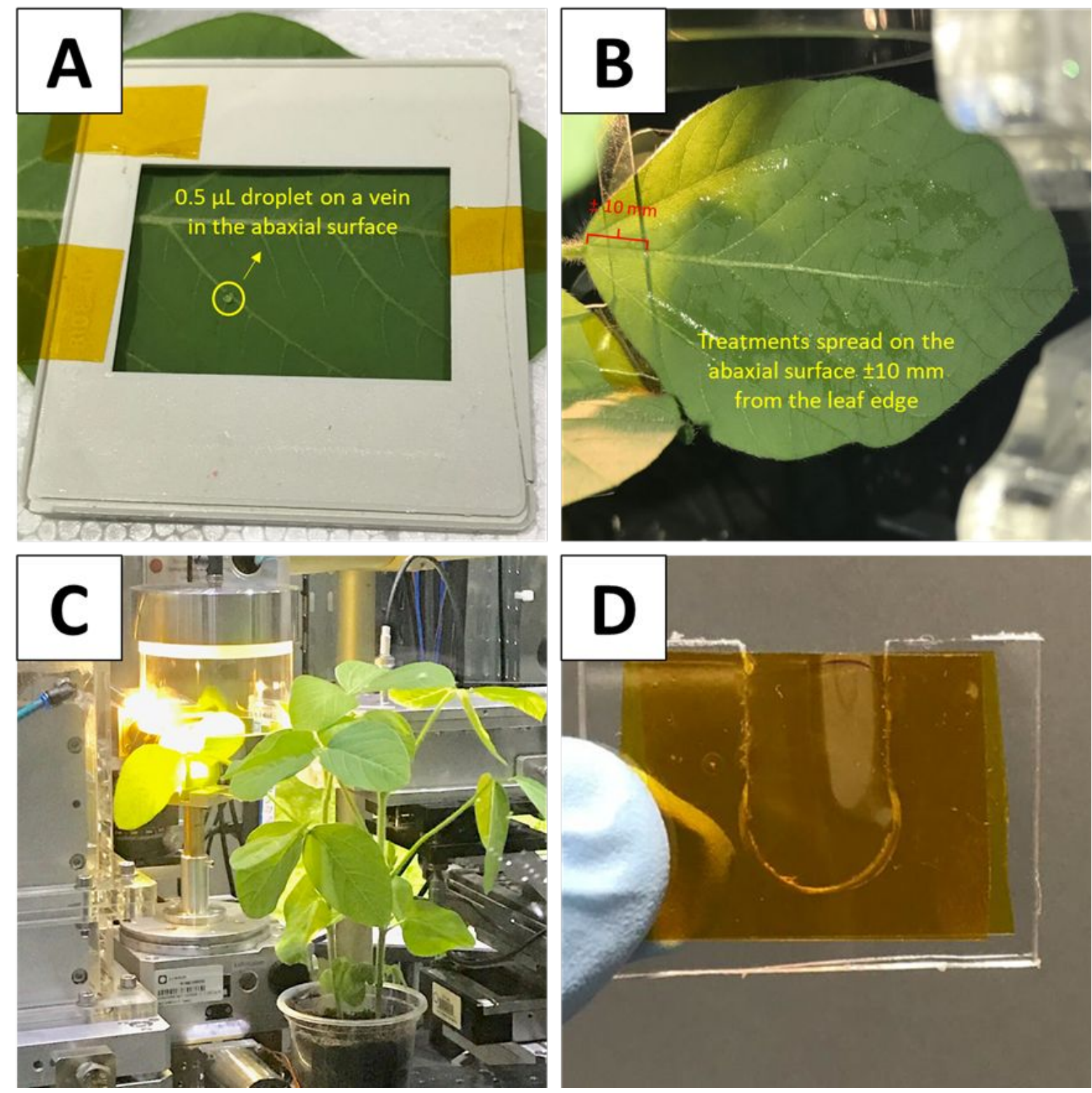

Figure S4. (A) Fertilizer droplet just after the applications; (B) Spreading of the fertilizer on the soybean leaf; (C) Soybean plant loaded in the beamline; (D) Set up of the cell used for measurements in liquids samples. 


\section{Zn reference compounds}

Follow below are the spectra of the $\mathrm{Zn}$ malate and sulphate standards, evidencing that the spectra recorded in solution media presented higher whiteline than the solid counterparts.

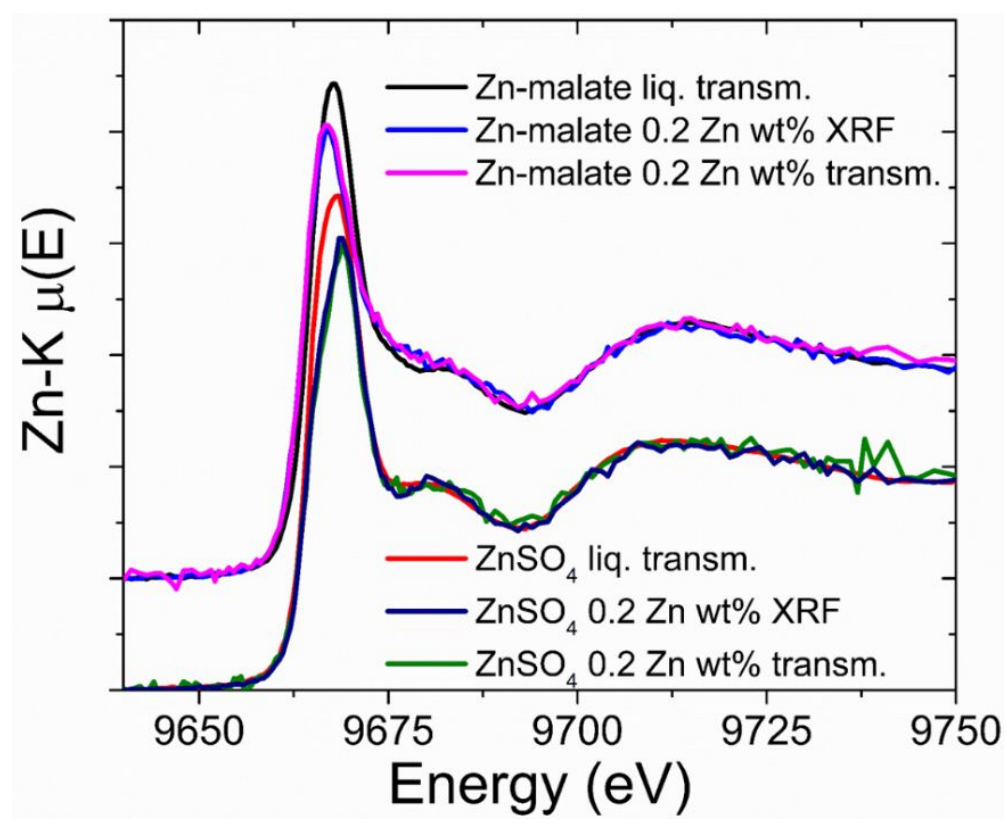

Figure S5. XANES spectra of the Zn malate and sulphate standards, highlighting that the spectra recorded in solution media presented higher whiteline than the solid counterparts.

\section{Scanning Electron Microscopy}

The scanning electron microscope images were taken on the Structural Characterization Laboratory of the University of São Carlos in São Carlos - SP. The fertilizer was dripped directly on an aluminum foil assembled on a sample holder and dried in air for 24 hours. The readings were performed on the Magellan 400 L EDAX Ametek USA facility. The images demonstrated a wide diversity of particles sizes and shapes close to parallelepipeds and spheres (Figure S6). , 


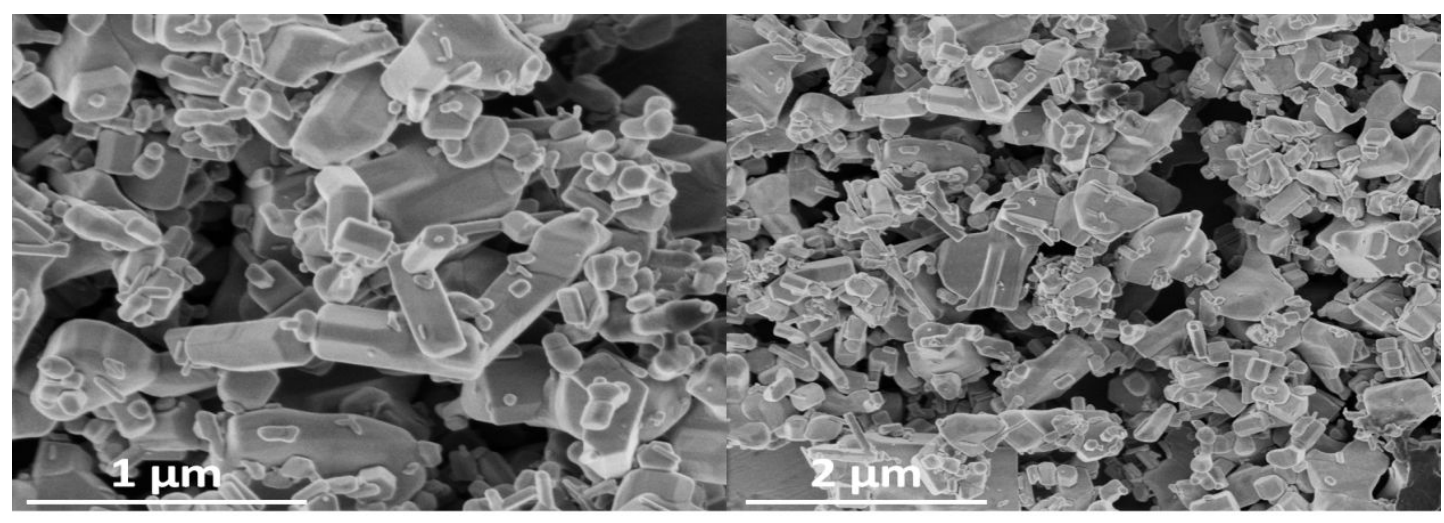

Figure S6. Scanning Electron Microscope images of the commercial $\mathrm{ZnO}$ fertilizer.

\section{X-Ray Diffraction Spectroscopy}

Aiming at determining the crystallite size of the $\mathrm{ZnO}$ tested it as performed XRD analysis. The $\mathrm{ZnO}$ diffractograms is presented on Figure S17 and the different plane sizes of the crystallites is on Table S2. The instrumental broadening was subtracted. These sizes were determined using the Scherrer equation (Equation S2).

$D(n m)=\frac{K \lambda}{\beta \cos \theta}$

$D$, crystallite size in nanometers

$\mathrm{K}$, Scherrer constant ( 0.94 for spherical crystals with cubic symmetry);

$\lambda$, wavelength of light used for the diffraction $(0.154184 \mathrm{~nm}$ to $\mathrm{Cu})$;

$\beta$, FWHM (full width at half maximum) of the peak;

$\theta$, angle measured.

The $\mathrm{ZnO}$ showed an elongated form, close to a parallelepiped corroborating the shape observed in Figure S6. 


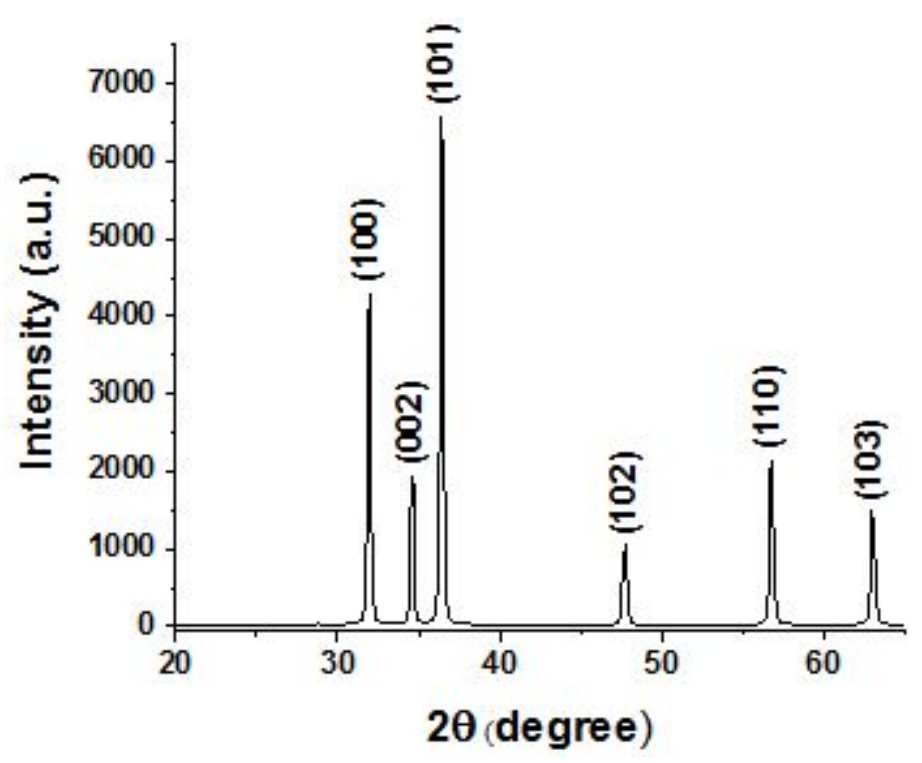

Figure S7. XRD pattern of the commercial ZnO tested.

Table S2. Crystallite size (D) in different planes for XRD data of the $\mathrm{ZnO}$ used in this study. The hkl stands for the Miller indexes.

\begin{tabular}{cc}
\hline Plane (hkl) & D (nm) \\
\hline 100 & 34,72 \\
002 & 24,85 \\
101 & 33,39 \\
\hline
\end{tabular}

10. Dynamic Light Scattering

The DLS analysis was carried out on the Nanotechnology National Laboratory in Campinas - SP. The fertilizer was diluted up to $100 \mathrm{mg} \mathrm{L}^{-1}$ and an aliquot of approximately $30 \mathrm{~mL}$ was transferred to a Polystyrene Cuvette (DTS 0012, Malvern Company). Then the cuvette was loaded in the Zetasizer Nano Range Malvern company equipment which operated using water as dispersant (viscosity of $0.8872 \mathrm{cP}$ and refractive index of 1.33), reading time of 60 seconds and frequency of $398 \mathrm{k}$ counts per second (kcps). The analysis demonstrates one peak at 481,1 $\pm 118,2 \mathrm{~nm}$. 


\section{Solubility}

The partial of soluble $\mathrm{Zn}$ in the fertilizer was determined analyzing its concentration in the original fertilizer with and without centrifugation by XRF technique using thin film method. The fertilizer was transferred to two plastic vials of $1 \mathrm{~mL}$, centrifuging one of them for 1 hour at 13.000 rotations per minute on a centrifuge machin (Mikro 120, Hettich Instruments). Then, $950 \mu \mathrm{L}$ of each sample was transferred to other vials adding $50 \mathrm{uL}$ of the $1,003 \mathrm{mg} \mathrm{Ga} \mathrm{L}^{-1}$ internal standard (1:10 dilution from Aldrich $10,030 \mathrm{mg} \mathrm{Ga} \mathrm{L}^{-1}$ ). Fifteen $\mathrm{mL}$ of the final solutions were dripped up to a 6.3 mm window XRF cuvette (no. 3577 - Spex Ind. Inc., USA) sealed with $5 \mu \mathrm{m}$ thick PP film (no. 3520 - Spex Ind. Inc., USA), and then analyzed on an energy dispersive Xray spectrometry (EDX720, Shimadzu, Japan). Aiming at checking the results obtained, the procedure was repeated with $\mathrm{ZnSO}_{4(\mathrm{aq})}$, with recovery of 99,5\%.

It was observed that just $0.04 \%$ of the $\mathrm{Zn}$ in the fertilizer was soluble in water (Table S3).

Table S3. Zinc concentration on the fertilizer with and without centrifugation

\begin{tabular}{cc}
\hline Treatment & Zn concentration $\left(\mathbf{m g ~ L}^{-1}\right)$ \\
\hline - Centrifugation & 521,000 \\
+ Centrifugation & 196 \\
\hline
\end{tabular}

12. Penetration pathways thought the leaf blade

Follow bellow is a scheme of a transversal cut of a soybean leaf illustrating the possible pathways of penetration of solutes.

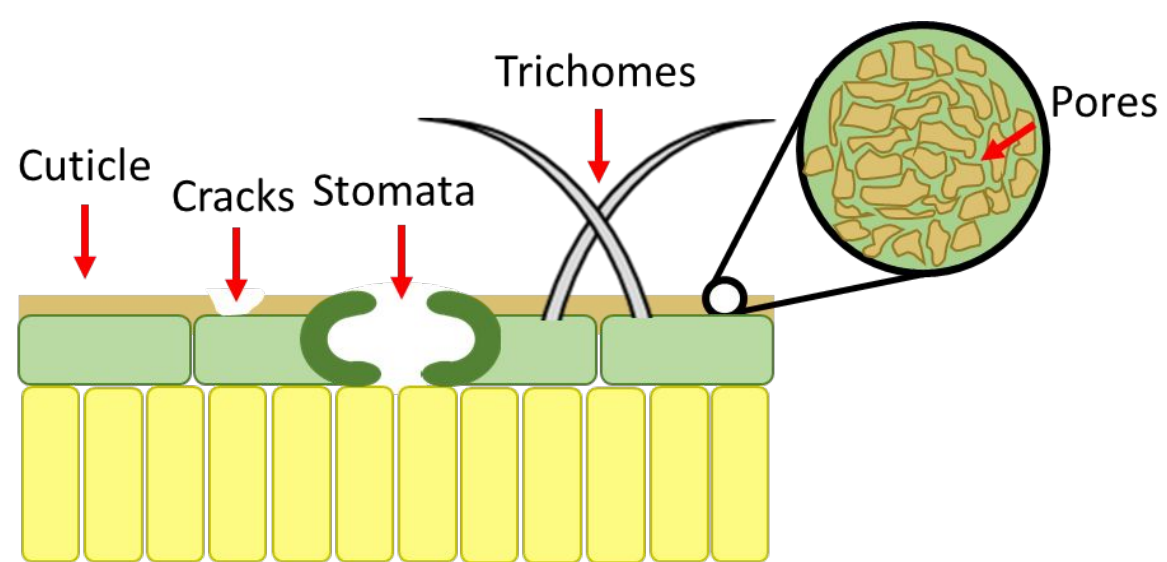

Figure S8. Scheme of a transversal view of a soybean leaf and the possible pathways of penetration of solutes. 


\section{Contact angle}

The contact angle was measure to determine the contact surface between the fertilizer and the leaves, which influence directly the interaction between them and consequently the foliar uptake of nutrients.

It was performed on the University of São Carlos in Sorocaba - SP using a Goniometer/Tensiometer (Model 500 Advanced, Ramé-hart, USA, Figure S8A). For analysis, $5 \mu \mathrm{l}$ droplets of each fertilizer at $2,300 \mathrm{mg} \mathrm{L}^{-1}$ of Zinc was applied up to the abaxial face of the leaf and elapsed one minute for stabilization (Figure S8B, it was performed the measurements in triplicate. The results were analyzed on the DROP image Advanced software and demonstrate that the contact angle of the droplets was close $142 \pm 6^{\circ}$ and $140 \pm 2^{\circ}$ for $\mathrm{ZnO}$ and $\mathrm{ZnSO}_{4(\text { aq) }}$ respectively (Figure S8C).

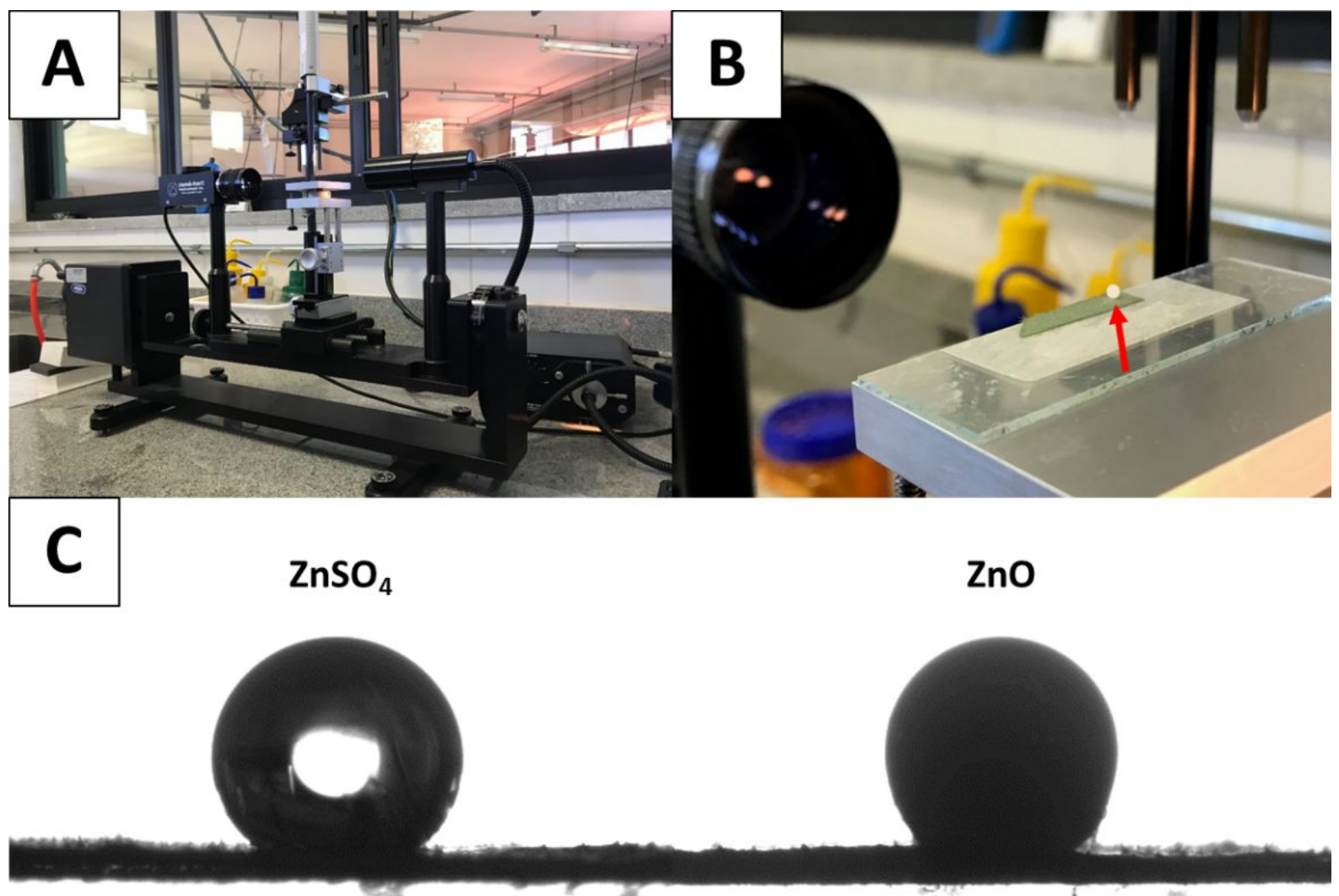

Figure S9. (A) Ramé-hart Model 500 Advanced Goniometer/Tensiometer equipment; (B) Set up of the droplet for analysis; (C) Images of the $\mathrm{ZnSO}_{4}$ and $\mathrm{ZnO}$ droplets dripped on the abaxial face of a soybean leaf. 


\section{Drying time}

The drying time was determined taking pictures of droplets of the fertilizers applied on the abaxial face of a leaf each 2 minutes. Each droplet had $5 \mu \mathrm{l}$ and 2.300 $\mathrm{mg} \mathrm{L}^{-1}$ of Zinc. The pictures were taken by a D3100 Nikon camera with an 18-55 mm lengths. It was observed that even containing additives, the drying time of the oxide was lower than the sulphate, 60 and 90 minutes respectively (Figure S9).

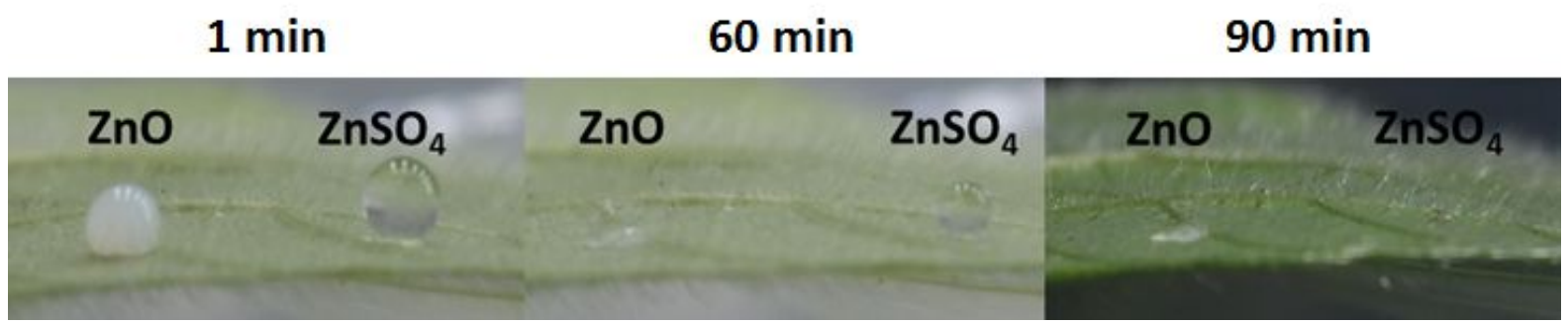

Figure S10. Pictures of the $\mathrm{ZnO}$ and $\mathrm{ZnSO}_{4}$ droplets elapsed 1, 60 and 90 minutes of the application.

\section{5. $\mathrm{pH}$}

The $\mathrm{pH}$ was determined using a $\mathrm{pH}$ meter (SevenGo Duo, Mettler Toledo). The fertilizers were transferred to $50 \mathrm{~mL}$ beckers and diluted up to $2,300 \mathrm{mg} \mathrm{L}^{-1}$ using deionized water. Then, the measurements were performed introducing the equipment electrode directly on the fertilizer suspension/solution. The readings demonstrate $\mathrm{pH}$ values of 7.0 and 6.1 for $\mathrm{ZnO}$ and $\mathrm{ZnSO}_{4}$, respectively.

\section{Radiation Damage}

\subsection{XRF Measurements}

Figure S11 presents series of XANES spectra recorded at the leaf blade of two control plants. 

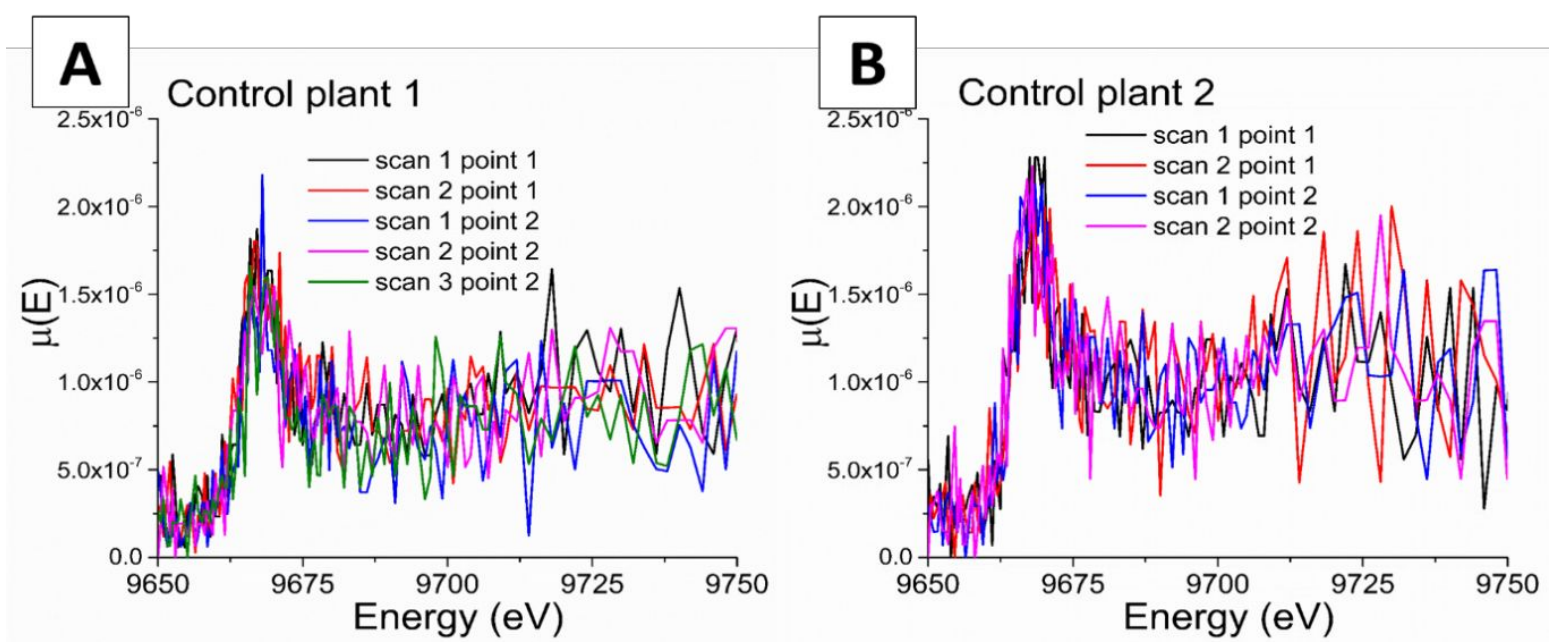

Figure S11. Series of XANES spectra recorded at the leaf blade of two control plants.

In Figure S12 is highlighted the bremsstrahlung scattering recorded at the $\mathrm{Zn}$ Ka ROI for leaf blades irradiates with an X-ray bead produced by a Rh tube at different tensions.
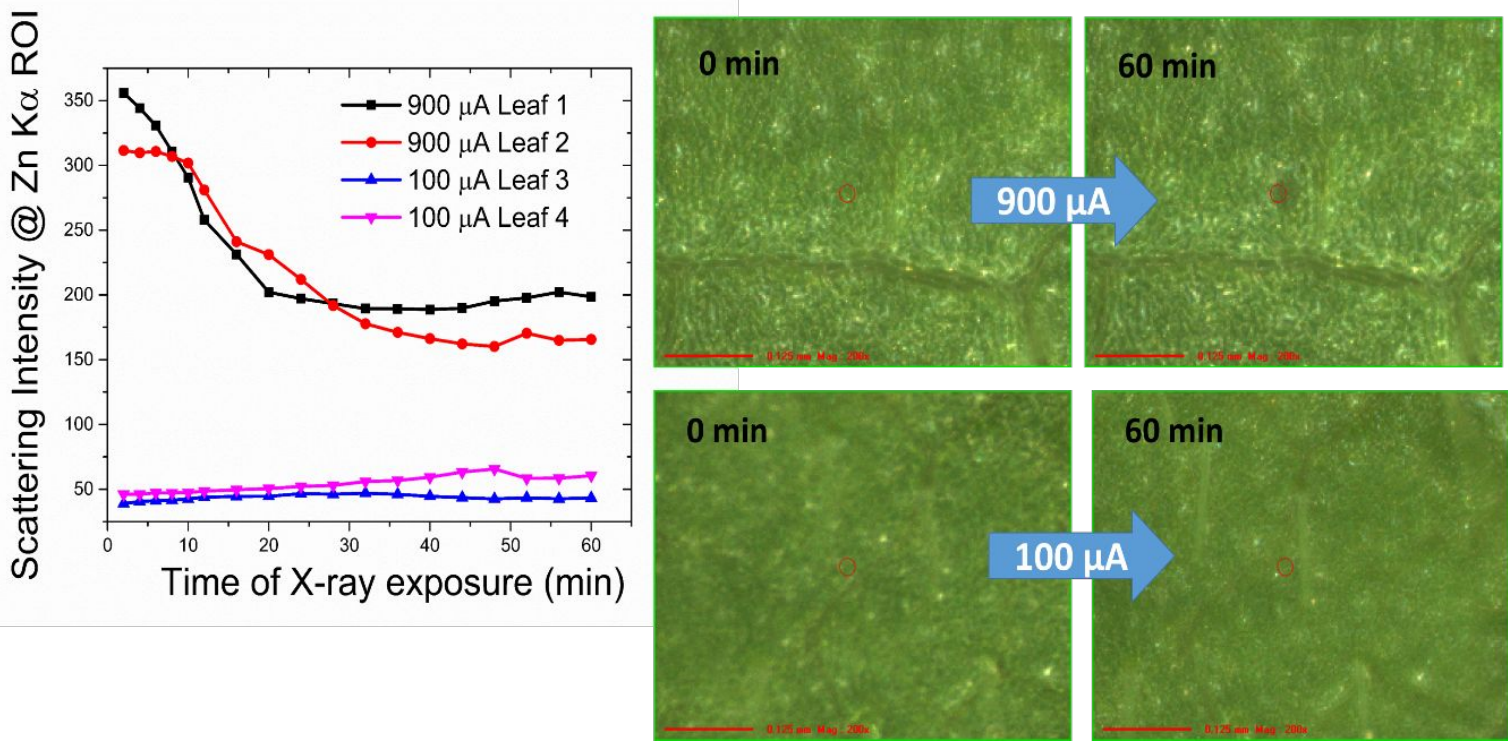

Figure S12. X-ray bremsstrahlung scattering recorded at the Zn Ka ROI for leaf blades irradiated with an X-ray beam produced by a laboratory Rh anode operating at $900 \mu \mathrm{A}$ and $100 \mu \mathrm{A}$. 
Figure S13 presents pictures of the region on the lead blade where the XANES analysis were performed.

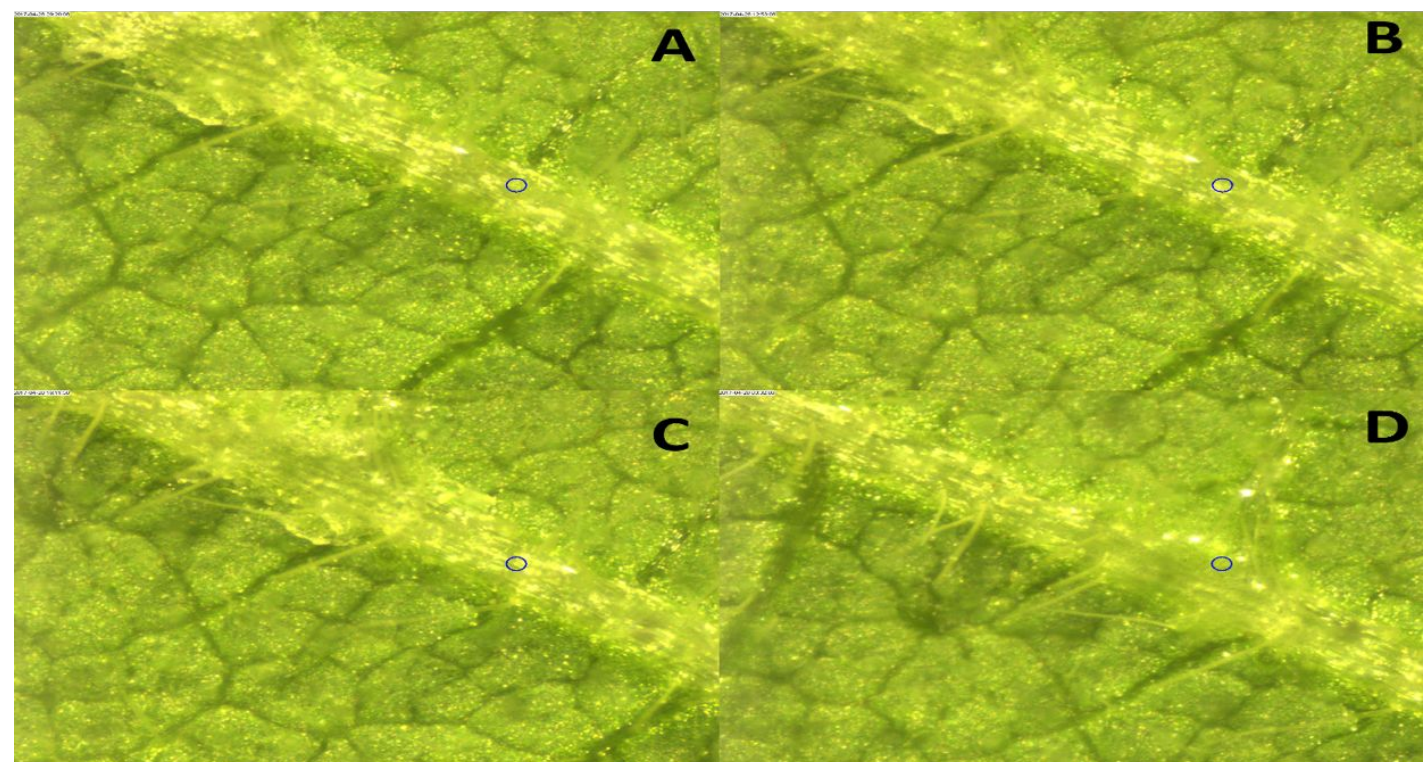

Figure S13. Pictures of region where the XANES measurements were taken on the leaf blade.

Figure S14 presents series of XANES spectra recorded at the petiole of two control plants.
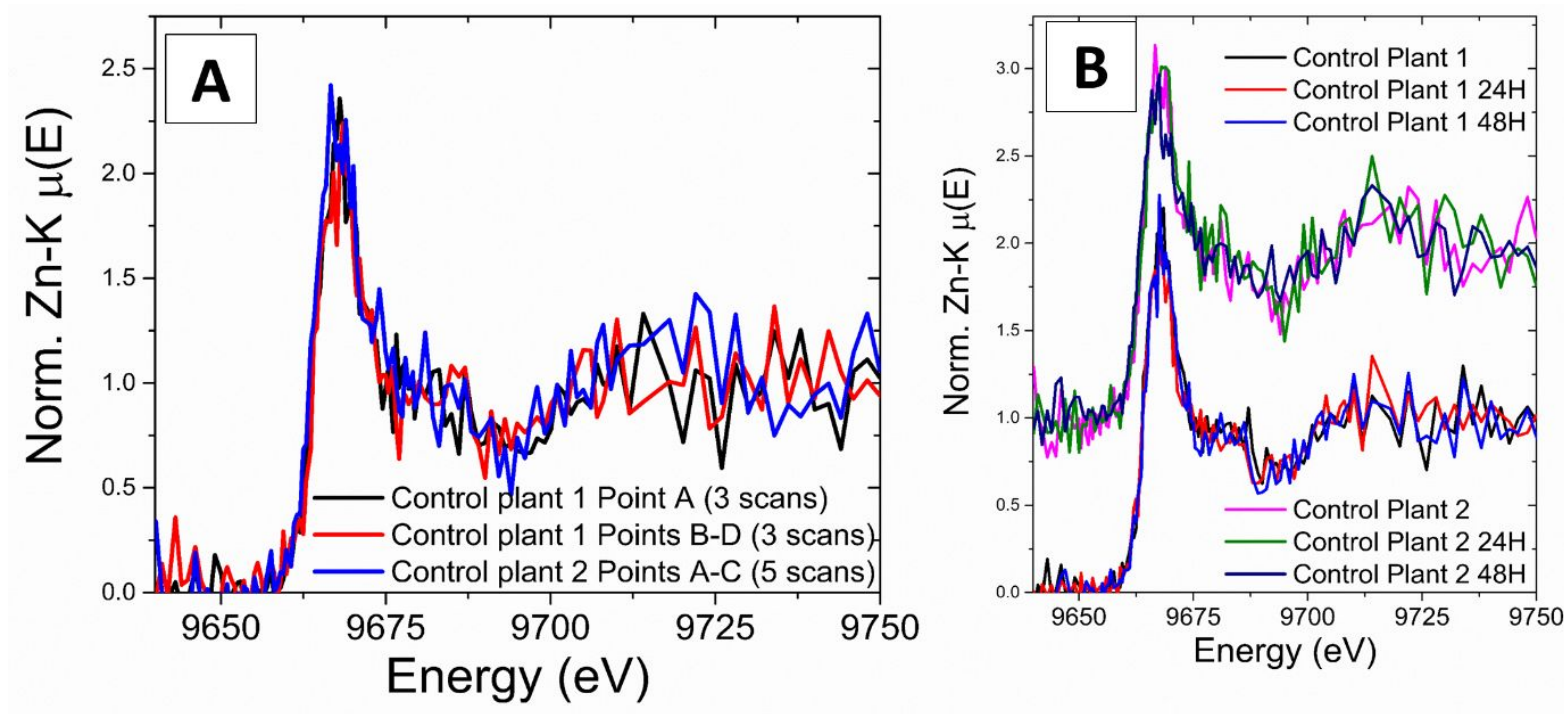

Figure S14. Series of XANES spectra recorded at the petiole of two control plants 
Figure S15 presents pictures of the region on the petiole where the XANES analysis were performed.

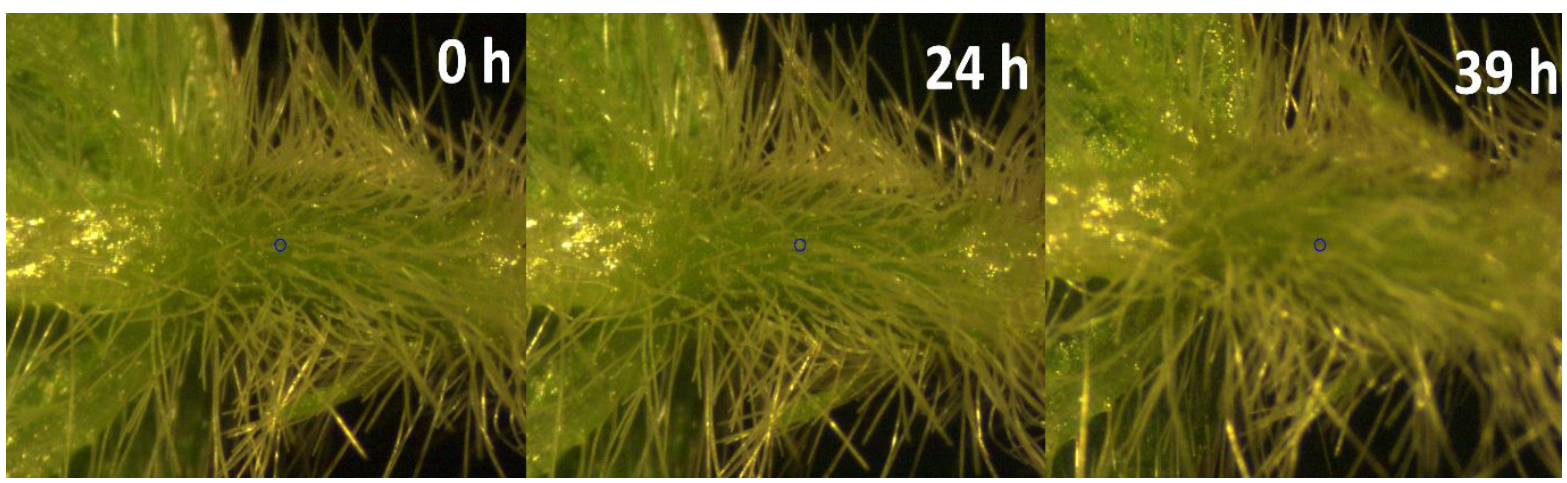

Figure S15. Pictures of region where the XANES measurements were taken on the petiole.

\subsection{Light Microscopy Analysis}

Portions of petioles at the irradiated point and nearby were fixed and vacuum infiltrated for 15 min. in a modified Karnovsky (1965) solution (2\% glutaraldehyde, 2\% paraformaldehyde, $5 \mathrm{mM} \mathrm{CaCl}_{2}$ in $0.05 \mathrm{M}$ sodium cacodylate buffer, $\mathrm{pH} 7.2$ ) for $48 \mathrm{~h}$ at $4 \circ \mathrm{C}$. Dehydration was conducted in increasing ethanol series, for $1 \mathrm{~h}$ each step $(30 \%-100 \%, 10 \%$ increase). Samples were embedded in historesin from Leica. Sections (5- $\mu \mathrm{m}$ thick) were obtained in a rotatory microtome (Leica RM2155, Nussloch, Germany), subsequently stained with $0.05 \%(\mathrm{w} / \mathrm{v})$ toluidine blue and mounted with Entellan® mounting media. Pictures were taken with a Zeiss Axioskop 40 HBO 50 A/C (Carl Zeiss, Jena, Germany).

The Cross-sections of petioles adjacent to the irradiation point are presented in Figure S16 and S17. The data of the petiole diameter measurements are present in Figure S18. 

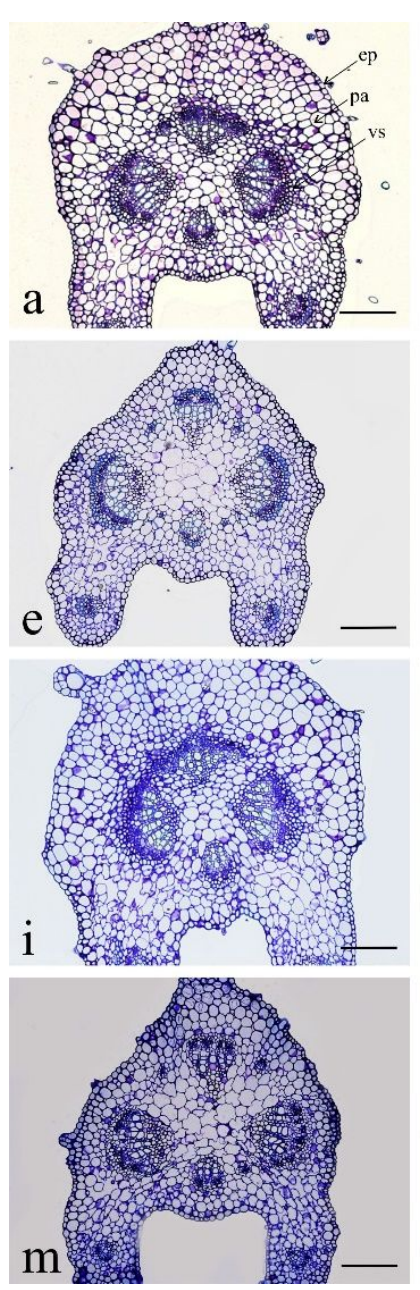
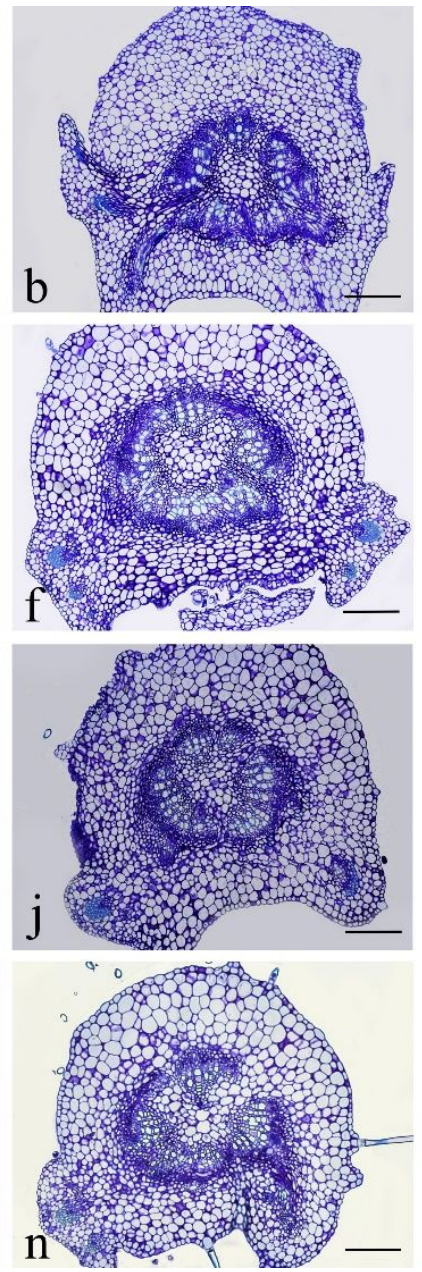
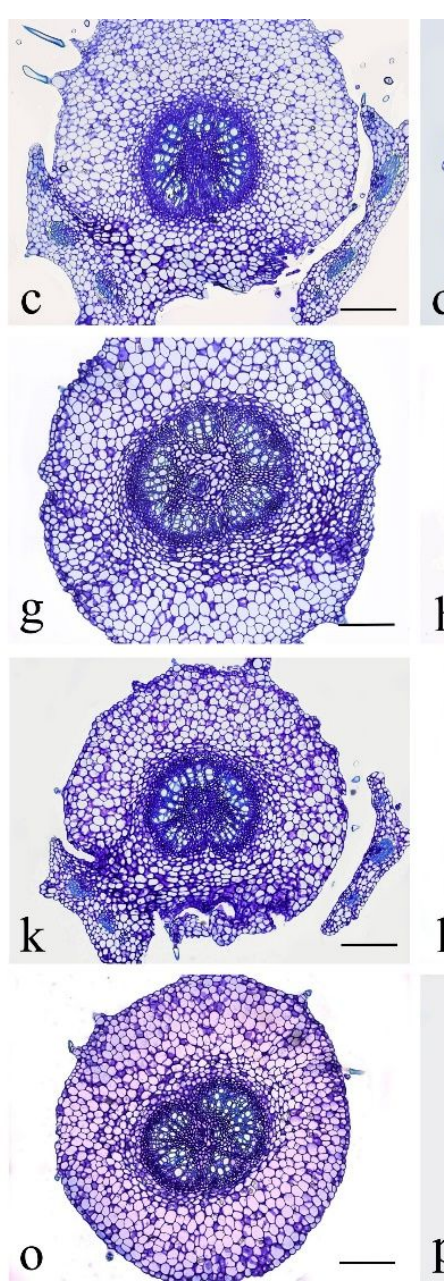
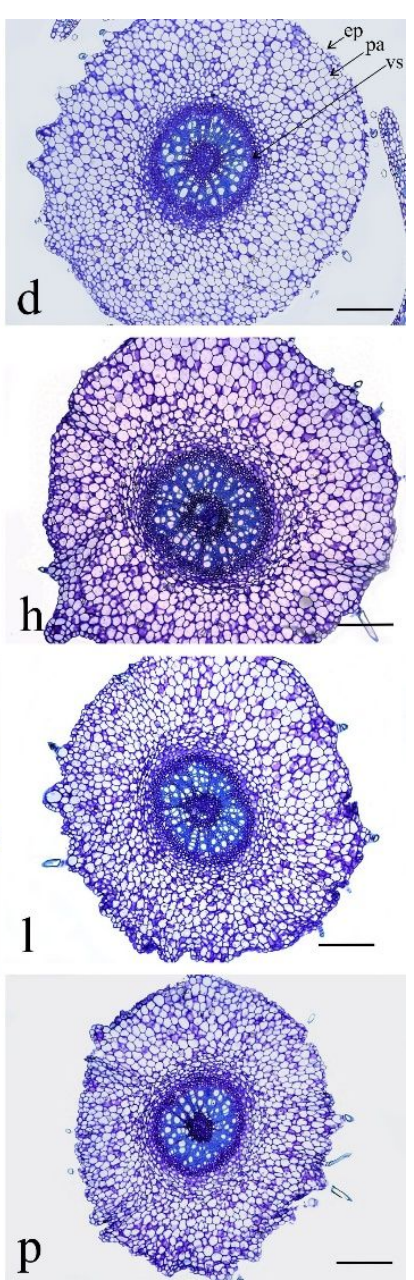

Figure S16. Cross-sections of petioles at the irradiated and adjacent sections; (a-d) non irradiated and non Zn-treated; (e-h) irradiated but not Zn-treated; (i-I) X-ray irradiated and treated with $2.3 \mathrm{~g} \mathrm{Zn} \mathrm{L}^{-1} \mathrm{ZnSO}_{4(\mathrm{aq})}$, (m-p) X-ray irradiated and treated with $23 \mathrm{~g} \mathrm{Zn} \mathrm{L}^{-1} \mathrm{ZnSO}_{4(\mathrm{aq})}$. The samples were irradiated by a $1 \mathrm{~mm} \mathrm{X-ray} \mathrm{beam} \mathrm{for} 90$ s and instrument operating at $40 \mathrm{kV}$ and $900 \mu \mathrm{A}$. Bar $\mathrm{l}=200 \mu \mathrm{m}$. 

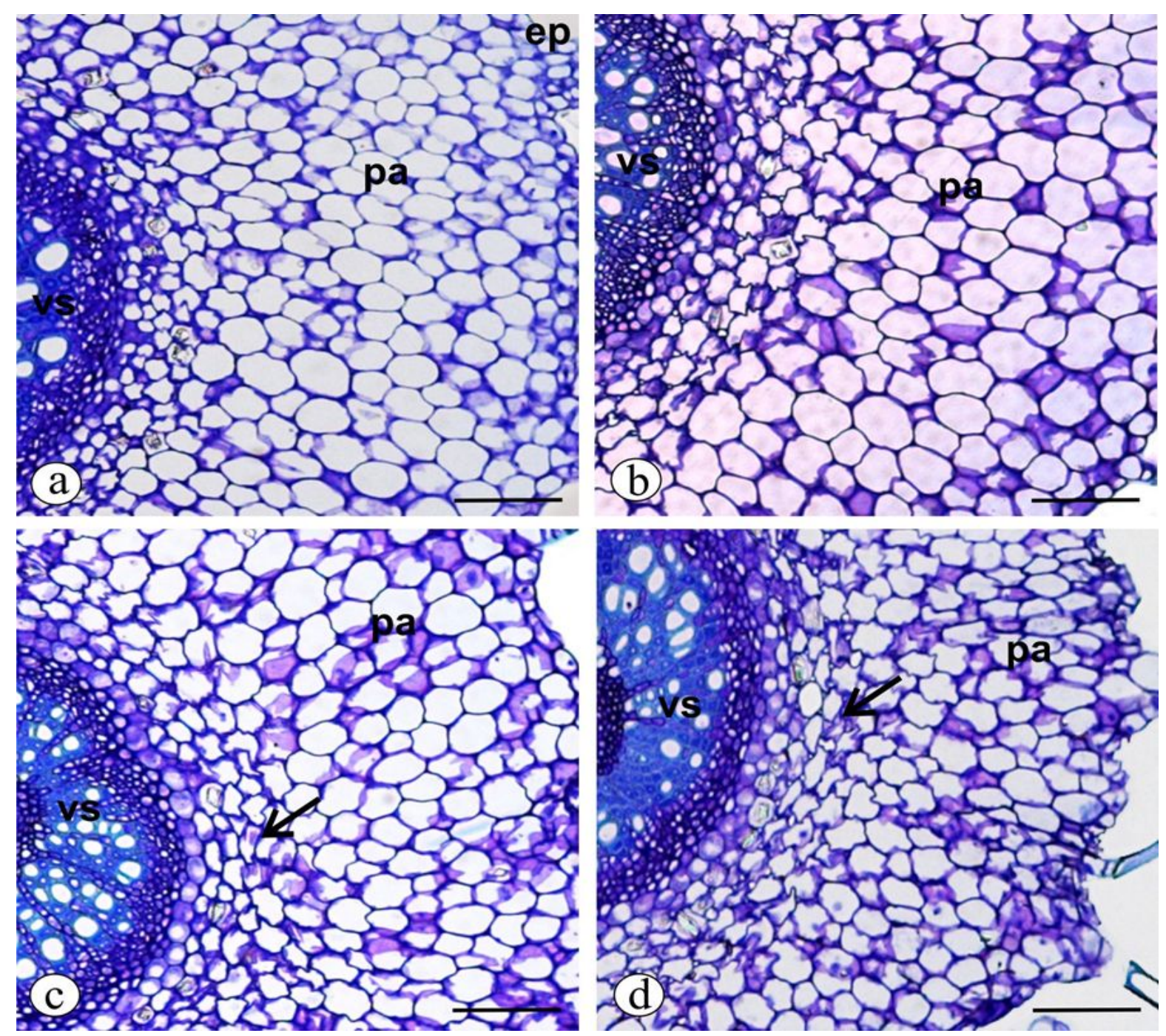

Figure S17. Detailing of petiole parenchyma cells adjacent to stem junction. a) Nonirradiated, non-treated control; b) X-ray irradiated, but non Zn-treated; c) X-ray irradiated and treated with $2.3 \mathrm{~g} \mathrm{Zn} \mathrm{L}^{-1} \mathrm{ZnSO}_{4(\mathrm{aq})}$; d) g-i) X-ray irradiated and treated

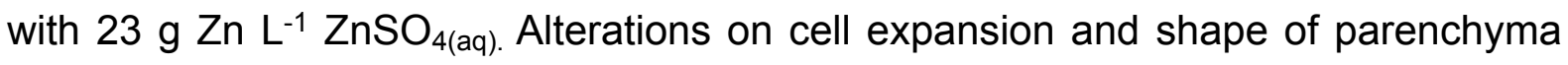
cells close the endodermis (arrows). ep: epidermis; pa: parenchyma; vs: vascular system. Bars: $50 \mu \mathrm{m}$. 


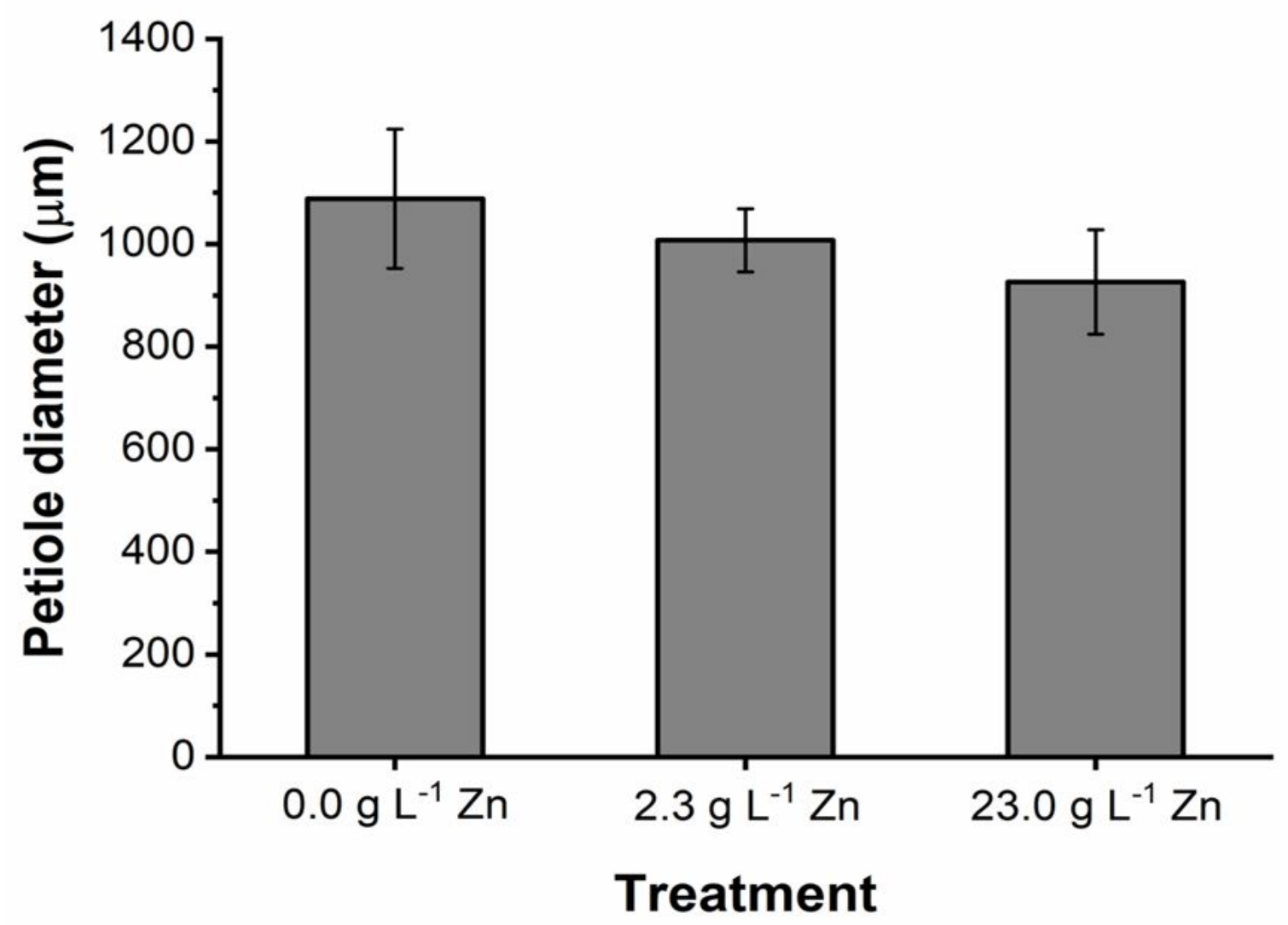

Figure S18. Effects of Zn-treatments on petiole diameter. 